\title{
Outcomes of hypofractionated stereotactic radiotherapy for metastatic brain tumors with high risk factors.
}

\section{$\operatorname{AUTHOR}(\mathrm{S}):$}

Ogura, Kengo; Mizowaki, Takashi; Ogura, Masakazu; Sakanaka, Katsuyuki; Arakawa, Yoshiki; Miyamoto, Susumu; Hiraoka, Masahiro

\section{CITATION:}

Ogura, Kengo ...[et al]. Outcomes of hypofractionated stereotactic radiotherapy for metastatic brain tumors with high risk factors.. Journal of neuro-oncology 2012, 109(2): 425-432

\section{ISSUE DATE:}

2012-09

URL:

http://hdl.handle.net/2433/160382

\section{RIGHT:}

The final publication is available at www.springerlink.com; この論文は 出版社版でありません。引用の際には出版社版をご確認ご利用くださ $\omega_{\circ}$; This is not the published version. Please cite only the published version. 
Title Page

Outcomes of hypofractionated stereotactic radiotherapy for metastatic brain tumors with high risk factors

Author

Kengo Ogura, Takashi Mizowaki, Masakazu Ogura, Katsuyuki Sakanaka, Yoshiki Arakawa, Susumu Miyamoto, and Masahiro Hiraoka

Affiliation

Kengo Ogura, Takashi Mizowaki, Masakazu Ogura, Katsuyuki Sakanaka, Masahiro Hiraoka

Department of Radiation Oncology and Image-applied Therapy, Kyoto University Graduate School of Medicine, 54 Kawahara-cho Shogoin Sakyo-ku, Kyoto, 606-8507, JAPAN

Yoshiki Arakawa, Susumu Miyamoto

Department of Neurosurgery, Kyoto University Graduate School of Medicine, Kyoto, JAPAN

Corresponding to Takashi Mizowaki

e-mail:mizo@kuhp.kyoto-u.ac.jp 


\section{Abstract}

The present study aimed to analyze outcomes of hypofractionated stereotactic radiotherapy (HFSRT) delivered in five fractions to metastatic brain tumors. Between June 2008 and June 2011, 39 consecutive patients with 46 brain metastases underwent HFSRT at Kyoto University Hospital. Selection criteria included high risk factors such as eloquent location, history of whole-brain radiotherapy (WBRT), or large tumor size. Given these factors, fractionated schedules were preferable in terms of radiobiology. The prescribed dose at the isocenter was basically $35 \mathrm{~Gy}$ in five fractions. Brainstem lesions with a history of WBRT were treated with 20-25 Gy in five fractions. Planning target volume was covered by the $80 \%$ isodose line of the prescribed dose to the isocenter. Local-control probability and overall survival were estimated using the Kaplan-Meier method. For the analysis of local control, the response criteria were defined as follows: complete response (CR) was defined as no visible gross tumor or absence of contrast enhancement, partial response (PR) as more than a $30 \%$ decrease in size, progressive disease (PD) as more than a $20 \%$ increase in size, and stable disease (SD) as all other responses. Local control was defined as a status of CR, PR, or SD. Only patients with at least 3 months or longer follow-up (21 patients, 27 tumors) were included in the analysis. Median age and Karnofsky performance status were 59 years (range, 39-84 years) and 90 (range, 40-100), respectively. Tumor volumes and maximum diameters ranged from 0.08 to $15.38 \mathrm{cc}$ (median, $3.67 \mathrm{cc}$ ) and from 3 to $34 \mathrm{~mm}$ (median, $18 \mathrm{~mm}$ ), respectively. The median follow-up period was 329 days (range, 120-1321 days). Local-control probabilities at 6 and 12 months were $92.1 \%$ and $86.7 \%$, respectively. Overall survival after HFSRT at 6 and 12 months was $85.4 \%$ and $64.5 \%$, respectively. Grade 3 radiation necrosis was observed in one patient according to the Common Terminology Criteria for Adverse Events version 3.0. The patient was successfully managed conservatively. HFSRT for metastatic brain tumors yields high local-control probabilities without increasing severe adverse events despite high risk factors. 


\section{Introduction}

Brain metastases are a commonly reported condition, occurring in $20-40 \%$ of patients with cancer [1]. Brain metastases may be symptomatic and can be the direct cause of death. Brain metastases are primarily treated with open surgery and radiotherapy. Radiotherapy strategies include whole-brain radiotherapy (WBRT) and/or stereotactic irradiation, depending on the clinical situation [2-6]. Stereotactic radiosurgery (SRS) yields high local-control rates for relatively small lesions. However, local control using a single-fraction dose becomes difficult as tumor size increases. Large tumors required a high dose for local control, and exposure of normal brain tissue to a high radiation dose increases the probability of late toxicities such as radiation necrosis [7]. Furthermore, lesions with a history of WBRT and those located in an eloquent area such as brainstem can increase the probability of the toxicity because normal brain tissue in these cases probably have a lower tolerance for irradiation and late toxicities should be more problematic in eloquent areas than non-eloquent areas [8]. Survival rates have increased as systemic therapies have improved [1]. More attention should be given to late toxicities under these conditions. Hypofractionated stereotactic radiotherapy (HFSRT) may provide a way to maintain high local-control rates without increasing late toxicities $[9,10]$. Recent advances in precision and the development of a less invasive fixation technique have increased the safety of irradiation using a fractionated schedule. The present paper reports the outcome of HFSRT treatment for metastatic brain tumors. 


\section{Materials and methods}

Patients and tumor characteristics

From June 2008 through July 2011, 39 consecutive patients with 46 brain metastases underwent HFSRT at Kyoto University Hospital. Inclusion criteria included high risk factors such as lesions in eloquent locations, prior history of WBRT, and large tumors (maximum diameter $>15 \mathrm{~mm}$ ). Eloquent lesions are defined as those located at or adjacent to the brainstem, basal ganglion, or motor areas. Of 39 patients, 21 with 27 lesions had follow-up magnetic resonance imaging (MRI) scans at least once 3 months or more after HFSRT and were included in the analysis. The remaining 18 patients could not undergo follow-up MRI scans because of poor performance status. Eligible patient and tumor characteristics are summarized in Table 1. According to the Radiation Therapy Oncology Group (RTOG) recursive partitioning analysis (RPA) [11], the majority of patients in our study (17/21 patients, $81 \%)$ were classified as class II.

Treatment

The treatment was performed using the Novalis system equipped with the ExacTrac system ver. 5.02 and Robotic Tilt Module mounted on the Exact Couch top (BrainLAB AG, Feldkirchen, Germany). Patients were immobilized in a thermoplastic stereotactic head mask with an additional bite block and infrared reflecting markers (BrainLAB AG). Computerized tomography (CT) images of 1.25-mm slice thickness were acquired using a Light Speed RT scanner (GE Healthcare, Milwaukee, WI, USA). Contrast-enhanced MRI scans were also referred with CT-MRI fusion devices. The gross tumor volume (GTV) was defined as the contrast-enhanced lesion detected in CT/MRI images. The clinical target volume (CTV) was defined as being identical to the GTV. The planning target volume (PTV) was formed by expanding the CTV with a 1-mm margin. This margin was evaluated using upfront analysis of the geometric accuracy of frameless stereotactic radiotherapy systems in our hospital [12]. All lesions were treated using a dynamic conformal arc technique with multileaf collimator (MLC) margin 0-1 mm, planned with iPlan RT Dose 4.1.2 (BrainLAB AG). Three or four arc beams were used. Patients were positioned using the Novalis/ExacTrac system. Positional errors including translations and rotations were corrected by 
moving the robotic couch. The prescribed doses were specified at the isocenter, and 35 Gy in five fractions was basically prescribed. Brainstem lesions with a prior history of WBRT were treated with lower doses: 20-25 Gy in five fractions was prescribed. PTV was covered by the $80 \%$ isodose line of the prescribed dose to the isocenter. One lesion was exceptionally treated with 40 Gy in five fractions at the discretion of the treating physician.

Follow-up and analysis

After treatment, patients underwent a follow-up MRI scan every 1-3 months, and the maximum diameter of the irradiated lesion in the axial image was measured. Twenty-one patients with 27 lesions had follow-up MRI scans at least once 3 months or more after HFSRT and were eligible for the analysis of local-control probability, probability of developing new brain metastases, overall survival, and time to neurological deterioration in the present study. For the analysis of local control, the response criteria were defined as follows: complete response (CR) was defined as no visible gross tumor or absence of contrast enhancement, partial response (PR) as more than a $30 \%$ decrease in size, progressive disease (PD) as more than a $20 \%$ increase in size, and stable disease (SD) as all other responses. Local control was defined as a status of CR, PR, or SD. Radiation necrosis/injury was defined as lesions in which the contrast-enhanced MRI images were enhanced peripherally or heterogeneously and resulted in no continuous progression on further follow-up. A nuclear medicine study such as positron-emission tomography was conducted as necessary. Open surgery and pathological diagnosis was recommended for lesions that caused clinical symptoms and could not be controlled conservatively. Radiation necrosis was not included in the PD category in the analysis of local control.

Neurologic deterioration was defined a decline in the KPS of $\geq 30$ for at least 1 week or a decline in KPS from any baseline to $\leq 50$ for at least 1 week. If the KPS before HFSRT was $<70$, neurologic deterioration was defined as any decline in the KPS after HFSRT for at least 1 week. A temporal decline in KPS that was attributable to other causes and not to a neurologic deficit was excluded. The cause of death was considered a neurologic cause if the patient had progressive neurologic dysfunction with or without progressive systemic disease. 


\section{Statistics}

Local-control probability, probability of developing new brain metastases, and overall survival were calculated using the Kaplan-Meier method. The local control probability and the probability of developing new brain metastases were evaluated from the initial HFSRT treatment to the date of failure or last imaging follow-up. Overall survival was measured from the initial HFSRT to the date of death or last follow-up. Time to neurological deterioration was measured from the date of the initial HFSRT to the date of neurological deterioration, death, or last follow-up. 


\section{Results}

Local control and new lesion development

The median duration of imaging follow-up was 286 days (range, 92-1315 days). PTV and maximum diameter of the tumor ranged from 0.08 to $15.38 \mathrm{cc}$ (median, $3.67 \mathrm{cc}$ ) and from 3 to 34 $\mathrm{mm}$ (median, $18 \mathrm{~mm}$ ), respectively. With the exception of the brainstem lesions (5 lesions, 18.5\%), the PTV and maximum diameter were $0.44-15.38 \mathrm{cc}$ (median, 5.44 cc) and 9-34 mm (median, 23 $\mathrm{mm}$ ), respectively. Brainstem lesions are more likely to be symptomatic and lethal than lesions in other locations, even when they are relatively small [13]; thus, we treated the brainstem lesions as soon as possible. Of the 21 patients, $10(47.6 \%)$ with 15 of the 27 lesions $(55.6 \%)$ had a history of WBRT before receiving HFSRT. The time between the end of prior WBRT and the initiation of HFSRT was 563 days (69-1116 days). The dose fractionation of prior WBRT was 30 Gy in 10 fractions (seven patients), 37.5 Gy in 15 fractions (two patients), and 25 Gy in 10 fractions (one patient). All these patients underwent HFSRT as salvage for failed WBRT.

The local-control probabilities were $92.1 \%$ (95\% confidence interval [CI], 82.2-100) at 6 months and 86.7\% (95\% CI, 73.5-100) at 12 months (Fig. 1a). At the time of analysis, four lesions in four patients were diagnosed as PD (Table 1). All PD lesions had been treated with an irradiation schedule of 35 Gy in five fractions.

Eleven patients $(52.4 \%)$ had new brain metastases after the initial HFSRT treatment. The probability of developing new brain metastases was $45.4 \%(95 \% \mathrm{CI}, 18.1-63.6)$ at 6 months and $59.0 \%(95 \% \mathrm{CI}, 27.6-76.8)$ at 12 months (Fig. 1b).

Toxicity

According to the CTCAE version 3.0, no grade 3-4 acute toxicities occurred in our study. Two grade 2 seizures were observed: one transient partial convulsion and one general seizure. Grade 2 mild hemorrhages at the irradiated site were observed in three patients, and they were successfully managed conservatively. We observed late toxicity in one patient, who developed a grade 3 radiation necrosis associated with clinical symptoms. The patient had a metastatic tumor in the right frontal lobe derived from breast cancer. The tumor was treated with $40 \mathrm{~Gy}$ in five fractions. The 
patient had a history of WBRT (30 Gy in 10 fractions) performed 15 months prior to the HFSRT. Initially, the tumor appeared to gradually shrink, but the contrast-enhanced lesion emerged approximately 2 years after HFSRT with clinical symptoms, increased weakness, and gait impairment. Surgery was recommended by a specialized neurosurgeon, but the patient refused and was treated with conservative therapy. At present, the symptoms have improved, and the enhanced areas and surrounding edema have disappeared.

Overall survival and time to neurological deterioration

The median follow-up after HFSRT was 329 days (range, 120-1321 days). Overall survival was 85.4\% (95\% CI, 71.5-100) at 6 months and 64.5\% (95\% CI, 46.3-89.8) at 12 months (Fig. 1c). Time to neurological deterioration was a median of 316 days (range, $98-1011$ days).

Nine patients had died at the time of analysis. The cause of death was neurologic causes in four patients and progressive systemic cancer in five patients. Another three patients were lost to follow-up, and all had progressive intracranial diseases and neurologic dysfunction. The remaining nine patients are alive to date and all except one is free from neurologic symptoms. The one patient had neurologic deterioration due to progressive intracranial disease.

As to the seven patients with eight eloquent lesions, time to neurological deterioration was a median of 231 days (range, 98-651 days) after the initiation of HFSRT. Of them, four patients had one or two lesion(s) at the brainstem and three patients had a history of WBRT (30 Gy in 10 fractions). The intervals between the end of WBRT and the initiation of HFSRT were 69, 171, and 325 days. Three improved or had stable neurologic symptoms at the time of last follow-up: two had stable or improved oculomotor nerve impairment and one had no neurologic symptoms. The other had local brainstem failure at 434 days after HFSRT and also had rapidly growing multiple intracranial lesions that caused neurologic deterioration. In contrast, two of three patients with lesions at the motor area had no severe acute toxicity but had neurologic deterioration due to local or other progressive lesions within the brain. 


\section{Discussion}

Research in the 1990s suggested that hypofractionation had significant benefits over single-dose radiosurgery in terms of widening the therapeutic window between tumor control and late effects, particularly for malignant tumors [9,10]. Current noninvasive, sophisticated techniques such as HFSRT have enabled clinicians to deliver high radiation doses to lesions precisely and repeatedly.

Dose escalation using single-fraction radiosurgery is problematic because large tumors require high doses that may cause late neurological toxicities. The first dose-escalation study using single-fraction radiosurgery (Radiation Therapy Oncology Group Study 90-05; RTOG 90-05) [7] was conducted to establish the maximum tolerable dose for patients with recurrent, previously irradiated, primary brain tumors and brain metastases. Doses were prescribed to the $50-90 \%$ isodose line according to the maximum diameter of the tumor. The results showed that the maximum tolerable doses for SRS were $24 \mathrm{~Gy}, 18 \mathrm{~Gy}$, and 15 Gy for tumors with maximum diameters $\leq 20 \mathrm{~mm}, 21-30 \mathrm{~mm}$, and 31-40 mm, respectively. Thus, the dose for larger tumors was reduced when using single-dose SRS, although dose escalation would be desirable in terms of controlling larger tumors.

In daily clinical practice, lesions amenable to $\mathrm{SRS}$ are typically $<3 \mathrm{~cm}$ in maximum diameter [14], and local control has been reported to be influenced by tumor size [15-18]. However, the relationship between tumor size and local control is difficult to assess because lower doses are prescribed for larger tumors and higher doses for smaller ones. Thus, the relationship between tumor size and local control in relation to one fixed dose in a single fraction is not clear and is seldom addressed in the literature. For relatively small tumors $\leq 2 \mathrm{~cm}$, many reports have shown good local control rates by using single-fraction SRS [14]. However, a cut-off value for local control seems to exist in even small tumors $\leq 2 \mathrm{~cm}$. To our knowledge, there are two reports regarding this point of view [19,20]. One study by Chang et al. [19] showed that the threshold value was a maximum tumor diameter of $1 \mathrm{~cm}$. The maximum diameter of the treated lesions in that study was $2.1 \mathrm{~cm}$, and they were treated in a single fraction with a prescribed dose of 20-24 Gy to the periphery of the target. Chang and colleagues reported that the 1-year local-control rates were $86 \%$ in tumors with a diameter $\leq 1 \mathrm{~cm}$ and $56 \%$ in tumors with a diameter $>1 \mathrm{~cm}$ [19]. The local-control rates found in the larger-diameter group were low compared with previously reported rates [14], which may have been due to the authors' criteria for inclusion and local treatment 
failure. The other study by Shehata et al. [20] reported excellent local control with single-fraction SRS for $\leq 2 \mathrm{~cm}$ tumors. At the same time, they also found that tumor volume was a significant factor affecting tumor control in their multivariate analysis. The threshold value was $0.3 \mathrm{cc}$, which was equal to about $0.8 \mathrm{~cm}$ estimated diameter.

Evidence suggests that hypofractionation could overcome the disadvantages of single-fraction radiosurgery. Several investigators have reported good results for local control using various hypofractionation schedules [21-29]. We also achieved high local-control rates of $92.1 \%$ and $86.7 \%$ at 6 and 12 months, respectively, despite relatively large tumor diameters (median, $18 \mathrm{~mm}$ ), and four relapsed cases (Table 1), which were irradiated with 35 Gy in five fractions. Two of the tumors were derived from colon and renal cancers, which were thought to be radioresistant tumors. Additionally, all four patients with these lesions had uncontrolled extracranial lesions, and these unfavorable factors might be associated with undesirable outcomes, but the actual relationship between local control and its predictive factors was not clear in the present study. An increase in dose escalation may be necessary to obtain better local-control probabilities; however, our sample size was too small to confirm this notion.

Optimal fractionation schedules need to be determined. Wiggernraad et al. [29] conducted a systematic review of stereotactic fractionated radiotherapy in metastatic brain tumors using a modified linear-quadratic-cubic (LQC) model. The LQC model adjusted the LQ model to account for a more linear response at higher doses by adding an additional term proportional to the cube of the dose. They concluded that a biologically effective dose at an $\alpha / \beta$ value of 12 Gy $\left(\mathrm{BED}_{12}\right)$ of at least 40 Gy was needed for a 12-month local-control rate of $70 \%$ or greater. Most of the patients in our study received a dose of 35 Gy in five fractions. Using a classical LQ model, the $\mathrm{BED}_{12}$ of this dose fractionation is significantly lower than that of single dose fraction radiosurgery. For example, the $\mathrm{BED}_{12}$ of $25 \mathrm{~Gy}$ in a single fraction is $77.1 \mathrm{~Gy}$ according to the classical LQ model, and 35 Gy in five fractions corresponds to a $\mathrm{BED}_{12}$ of $55.4 \mathrm{~Gy}$. However, using the LQC model, both dose fractionations are the same, estimated as $\mathrm{BED}_{12}=53.0 \mathrm{~Gy}$. The peripheral doses of PTV, $80 \%$ of the prescribed dose at the isocenter, were 28 Gy in five fractions and 20 Gy in a single fraction. Both were calculated as a $\mathrm{BED}_{12}$ of 40 Gy. Thus, we obtained good local-control rates in our study, supporting the notion of a more linear response rate between cell survival and dose at higher doses. Application of the LQC model to clinical practice is reasonable when comparing the 
$\mathrm{BED}_{12}$ of HFSRT with that of SRS at high doses. Lower doses estimated using the classical LQ model should provide good local control of metastatic brain tumors despite large sizes.

The role of tumor size in the control of brain metastases was not clear in the present study. Aoyama et al. [23] reported tumor volume $>3 \mathrm{cc}$ (equal to about $1.8 \mathrm{~cm}$ estimated diameter) is a significant prognostic factor for local control. However, some aspects of their study were different from ours as follows: a fractionation schedule of 20-40 Gy in four fractions at the isocenter, setup accuracy and PTV margin of $2 \mathrm{~mm}$, and dose delivery without MLC. To our knowledge, no other study has described the relationship between tumor size and local control in HFSRT. We think that the rationale behind better local control in HFSRT is safe dose escalation for larger tumors and radiobiological benefit of fractionation. According to the LQC model, HFSRT enables deliver of the same effective doses for larger tumors as a high-single dose for smaller tumors. In addition, some radiobiological benefit, such as reoxygenation, also contributes to better outcomes. The interval between each fractionated dose allows hypoxic tumor cells to be aerobic and radiosensitive, and to be killed by subsequent dose fractions [10]. The maximum diameter in the present study was up to $34 \mathrm{~mm}$. Tumors within this range seem to be safely controlled and a cutoff may exist at much larger sizes. However, HFSRT for much larger tumors would be a remaining issue for the future evaluations.

Late toxicities such as radiation necrosis and radiation injury may be life-threatening. The exact rates of radiation necrosis are not known. One reason for this is the difficulty in differentiating between a radiation injury and a recurrence [30]. Few studies describe the method used to distinguish a radiation necrosis from a true recurrence in their analysis of local control in brain metastases. The judgment appears to be based on clinical factors in most studies, and many report crude rates of radiation necrosis of 5-10\% [29]. In the RTOG 90-05 study, radiation necrosis was frequently observed when large-volume tumors were irradiated with high doses that were not clinically tolerated. In our study, the crude rate of radiation necrosis was $3.7 \%$ (one lesion), which occurred in the lesion irradiated with a dose of 40 Gy in five fractions. This patient had a history of WBRT, 30 Gy in 10 fractions. Radiation necrosis was not observed in other lesions in our study in those treated with 20-35 Gy in five fractions, even though half of them had been previously irradiated with WBRT. Moreover, with the exception of lesions in the brainstem, the median PTV was relatively large (median $5.44 \mathrm{cc}$ ); however, we did not observe severe toxicity. 
To our knowledge, no reports have shown a direct comparison of the incidence of radiation necrosis between WBRT plus SRS and SRS alone. However, we have some suggestive data in the Japanese randomized controlled trial [5]. In this trial, 132 patients with one to four metastases, each less than $3 \mathrm{~cm}$ in diameter, were randomly assigned to receive up-front WBRT plus SRS (65 patients) or SRS alone (67 patients). As a result, more patients treated with SRS plus WBRT developed radiation necrosis (three patients) than patients treated with SRS alone (one patient), although the SRS dose was reduced by 30\% in SRS plus WBRT group compared with SRS alone group. This observation suggests WBRT followed by SRS may result in increasing the risk of radiation necrosis.

A reduction in late toxicity is crucial for long-term survival. Patients with primary tumors such as renal cancer have been reported to have longer survival times than patients with other primary tumors [22], and more investigations should focus on the longer-surviving patients. Varlotto et al. [31] reported that the actuarial incidence of adverse events at 1 and 5 years was $2.8 \%$ and $11.4 \%$, respectively, in patients who had survived at least 1 year after radiosurgery for brain metastases. In our study, nine patients survived more than 1 year after HFSRT. One patient, who was treated with 40 Gy in five fractions, developed radiation necrosis. The sample size in our study was small, but 35 Gy in five fractions appears to be a safe dose.

The small sample size in the present study and limitations imposed by retrospective analyses do not allow us to definitively state that metastatic tumor treatment with HFSRT is superior to SRS. However, a randomized trial to compare these two methods would be unethical considering the toxicity of the higher doses in SRS. Nonetheless, a prospective study to determine optimal dose and fractionation schedules is warranted. Our results demonstrate the potential of HFSRT in terms of tumor-control probability and reduction in toxicities as a treatment for metastatic brain tumors with high risk factors. 


\section{Conclusions}

We conclude that HFSRT is safe and produces high local-control rates for metastatic brain tumors with high risk factors. We will continue to use this fractionation schedule for these difficult cases and conduct long-term follow-up to evaluate the efficacy of this strategy. 


\section{Acknowledgements}

This work was supported in part by Grants-in-Aid for Scientific Research from the Ministry of Education, Culture, Sports, Science, and Technology of Japan (20229009). 


\section{References}

1. Soffietti R, Ruda R, Trevisan E (2008) Brain metastases: current management and new developments. Curr Opin Oncol 20 (6):676-684. doi:10.1097/CCO.0b013e32831186fe [doi]

00001622-200811000-00012 [pii]

2. Patchell RA, Tibbs PA, Regine WF, Dempsey RJ, Mohiuddin M, Kryscio RJ, Markesbery WR, Foon KA, Young B (1998) Postoperative radiotherapy in the treatment of single metastases to the brain: a randomized trial. JAMA 280 (17):1485-1489. doi:joc80445 [pii]

3. Patchell RA, Tibbs PA, Walsh JW, Dempsey RJ, Maruyama Y, Kryscio RJ, Markesbery WR, Macdonald JS, Young B (1990) A randomized trial of surgery in the treatment of single metastases to the brain. N Engl J Med 322 (8):494-500. doi:10.1056/NEJM199002223220802 [doi]

4. Andrews DW, Scott CB, Sperduto PW, Flanders AE, Gaspar LE, Schell MC, Werner-Wasik M, Demas W, Ryu J, Bahary JP, Souhami L, Rotman M, Mehta MP, Curran WJ, Jr. (2004) Whole brain radiation therapy with or without stereotactic radiosurgery boost for patients with one to three brain metastases: phase III results of the RTOG 9508 randomised trial. Lancet 363 (9422):1665-1672. doi:10.1016/S0140-6736(04)16250-8 [doi]

S0140-6736(04)16250-8 [pii]

5. Aoyama H, Shirato H, Tago M, Nakagawa K, Toyoda T, Hatano K, Kenjyo M, Oya N, Hirota S, Shioura H, Kunieda E, Inomata T, Hayakawa K, Katoh N, Kobashi G (2006) Stereotactic radiosurgery plus whole-brain radiation therapy vs stereotactic radiosurgery alone for treatment of brain metastases: a randomized controlled trial. JAMA 295 (21):2483-2491. doi:295/21/2483 [pii] 10.1001/jama.295.21.2483 [doi]

6. Kocher M, Soffietti R, Abacioglu U, Villa S, Fauchon F, Baumert BG, Fariselli L, Tzuk-Shina T, Kortmann RD, Carrie C, Ben Hassel M, Kouri M, Valeinis E, van den Berge D, Collette S, Collette L, Mueller RP (2011) Adjuvant whole-brain radiotherapy versus observation after radiosurgery or surgical resection of one to three cerebral 
metastases: results of the EORTC 22952-26001 study. J Clin Oncol 29 (2):134-141. doi:JCO.2010.30.1655 [pii] 10.1200/JCO.2010.30.1655 [doi]

7. Shaw E, Scott C, Souhami L, Dinapoli R, Kline R, Loeffler J, Farnan N (2000) Single dose radiosurgical treatment of recurrent previously irradiated primary brain tumors and brain metastases: final report of RTOG protocol 90-05. Int J Radiat Oncol Biol Phys 47 (2):291-298. doi:S0360-3016(99)00507-6 [pii]

8. Williams BJ, Suki D, Fox BD, Pelloski CE, Maldaun MV, Sawaya RE, Lang FF, Rao G (2009) Stereotactic radiosurgery for metastatic brain tumors: a comprehensive review of complications. J Neurosurg 111 (3):439-448. doi:10.3171/2008.11.JNS08984 [doi]

9. Brenner DJ, Martel MK, Hall EJ (1991) Fractionated regimens for stereotactic radiotherapy of recurrent tumors in the brain. Int J Radiat Oncol Biol Phys 21 (3):819-824. doi:0360-3016(91)90703-7 [pii]

10. Hall EJ, Brenner DJ (1993) The radiobiology of radiosurgery: rationale for different treatment regimes for AVMs and malignancies. Int J Radiat Oncol Biol Phys 25 (2):381-385

11. Gaspar L, Scott C, Rotman M, Asbell S, Phillips T, Wasserman T, McKenna WG, Byhardt R (1997) Recursive partitioning analysis (RPA) of prognostic factors in three Radiation Therapy Oncology Group (RTOG) brain metastases trials. Int J Radiat Oncol Biol Phys 37 (4):745-751. doi:S0360-3016(96)00619-0 [pii]

12. Takakura T, Mizowaki T, Nakata M, Yano S, Fujimoto T, Miyabe Y, Nakamura M, Hiraoka M (2010) The geometric accuracy of frameless stereotactic radiosurgery using a 6D robotic couch system. Phys Med Biol 55 (1):1-10. doi:S0031-9155(10)30537-9 [pii] $10.1088 / 0031-9155 / 55 / 1 / 001[$ doi]

13. Kelly PJ, Lin YB, Yu AY, Ropper AE, Nguyen PL, Marcus KJ, Hacker FL, Weiss SE (2011) Linear accelerator-based stereotactic radiosurgery for brainstem metastases: the Dana-Farber/Brigham and Women's Cancer Center experience. J Neurooncol 104 (2):553-557. doi:10.1007/s11060-010-0514-0 [doi]

14. Linskey ME, Andrews DW, Asher AL, Burri SH, Kondziolka D, Robinson PD, Ammirati M, Cobbs CS, Gaspar LE, Loeffler JS, McDermott M, Mehta MP, Mikkelsen 
T, Olson JJ, Paleologos NA, Patchell RA, Ryken TC, Kalkanis SN (2010) The role of stereotactic radiosurgery in the management of patients with newly diagnosed brain metastases: a systematic review and evidence-based clinical practice guideline. J Neurooncol 96 (1):45-68. doi:10.1007/s11060-009-0073-4 [doi]

15. Matsuo T, Shibata S, Yasunaga A, Iwanaga M, Mori K, Shimizu T, Hayashi N, Ochi M, Hayashi K (1999) Dose optimization and indication of Linac radiosurgery for brain metastases. Int J Radiat Oncol Biol Phys 45 (4):931-939. doi:S0360-3016(99)00271-0 [pii]

16. Vogelbaum MA, Angelov L, Lee SY, Li L, Barnett GH, Suh JH (2006) Local control of brain metastases by stereotactic radiosurgery in relation to dose to the tumor margin. $\mathbf{J}$ Neurosurg 104 (6):907-912. doi:10.3171/jns.2006.104.6.907 [doi]

17. Schomas DA, Roeske JC, MacDonald RL, Sweeney PJ, Mehta N, Mundt AJ (2005) Predictors of tumor control in patients treated with linac-based stereotactic radiosurgery for metastatic disease to the brain. Am J Clin Oncol 28 (2):180-187. doi:00000421-200504000-00015 [pii]

18. Molenaar R, Wiggenraad R, Verbeek-de Kanter A, Walchenbach R, Vecht C (2009) Relationship between volume, dose and local control in stereotactic radiosurgery of brain metastasis. Br J Neurosurg 23 (2):170-178. doi:909741432 [pii] $10.1080 / 02688690902755613$ [doi]

19. Chang EL, Hassenbusch SJ, 3rd, Shiu AS, Lang FF, Allen PK, Sawaya R, Maor MH (2003) The role of tumor size in the radiosurgical management of patients with ambiguous brain metastases. Neurosurgery 53 (2):272-280; discussion 280-281

20. Shehata MK, Young B, Reid B, Patchell RA, St Clair W, Sims J, Sanders M, Meigooni A, Mohiuddin M, Regine WF (2004) Stereotatic radiosurgery of 468 brain metastases < or $=2 \mathrm{~cm}$ : implications for $\mathrm{SRS}$ dose and whole brain radiation therapy. Int $\mathrm{J}$ Radiat Oncol Biol Phys 59 (1):87-93. doi:10.1016/j.ijrobp.2003.10.009 [doi] S0360301603021138 [pii]

21. Manning MA, Cardinale RM, Benedict SH, Kavanagh BD, Zwicker RD, Amir C, Broaddus WC (2000) Hypofractionated stereotactic radiotherapy as an alternative to radiosurgery for the treatment of patients with brain metastases. Int J Radiat Oncol Biol Phys 47 (3):603-608. doi:S0360-3016(00)00475-2 [pii] 
22. Ikushima H, Tokuuye K, Sumi M, Kagami Y, Murayama S, Ikeda H, Tanaka M, Oyama H, Shibui S, Nomura K (2000) Fractionated stereotactic radiotherapy of brain metastases from renal cell carcinoma. Int J Radiat Oncol Biol Phys 48 (5):1389-1393. doi:S036030160000804X [pii]

23. Aoyama H, Shirato H, Onimaru R, Kagei K, Ikeda J, Ishii N, Sawamura Y, Miyasaka K (2003) Hypofractionated stereotactic radiotherapy alone without whole-brain irradiation for patients with solitary and oligo brain metastasis using noninvasive fixation of the skull. Int J Radiat Oncol Biol Phys 56 (3):793-800. doi:S0360301603000142 [pii]

24. Ernst-Stecken A, Ganslandt O, Lambrecht U, Sauer R, Grabenbauer G (2006) Phase II trial of hypofractionated stereotactic radiotherapy for brain metastases: results and toxicity. Radiother Oncol 81 (1):18-24. doi:S0167-8140(06)00423-3 [pii] 10.1016/j.radonc.2006.08.024 [doi]

25. Narayana A, Chang J, Yenice K, Chan K, Lymberis S, Brennan C, Gutin PH (2007) Hypofractionated stereotactic radiotherapy using intensity-modulated radiotherapy in patients with one or two brain metastases. Stereotact Funct Neurosurg 85 (2-3):82-87. doi:000097923 [pii]

$10.1159 / 000097923$ [doi]

26. Fahrig A, Ganslandt O, Lambrecht U, Grabenbauer G, Kleinert G, Sauer R, Hamm K (2007) Hypofractionated stereotactic radiotherapy for brain metastases--results from three different dose concepts. Strahlenther Onkol 183 (11):625-630. doi:10.1007/s00066-007-1714-1 [doi]

27. Kwon AK, Dibiase SJ, Wang B, Hughes SL, Milcarek B, Zhu Y (2009) Hypofractionated stereotactic radiotherapy for the treatment of brain metastases. Cancer 115 (4):890-898. doi:10.1002/cncr.24082 [doi]

28. Kim YJ, Cho KH, Kim JY, Lim YK, Min HS, Lee SH, Kim HJ, Gwak HS, Yoo H (2011) Single-dose versus fractionated stereotactic radiotherapy for brain metastases. Int J Radiat Oncol Biol Phys 81 (2):483-489. doi:S0360-3016(10)00756-X [pii] 10.1016/j.ijrobp.2010.05.033 [doi]

29. Wiggenraad R, Verbeek-de Kanter A, Kal HB, Taphoorn M, Vissers T, Struikmans H (2011) Dose-effect relation in stereotactic radiotherapy for brain metastases. A systematic review. Radiother Oncol 98 (3):292-297. doi:S0167-8140(11)00026-0 [pii] 
10.1016/j.radonc.2011.01.011 [doi]

30. Soussain C, Ricard D, Fike JR, Mazeron JJ, Psimaras D, Delattre JY (2009) CNS complications of radiotherapy and chemotherapy. Lancet 374 (9701):1639-1651. doi:S0140-6736(09)61299-X [pii] 10.1016/S0140-6736(09)61299-X [doi]

31. Varlotto JM, Flickinger JC, Niranjan A, Bhatnagar AK, Kondziolka D, Lunsford LD (2003) Analysis of tumor control and toxicity in patients who have survived at least one year after radiosurgery for brain metastases. Int J Radiat Oncol Biol Phys 57 (2):452-464. doi:S0360301603005686 [pii] 
Figure Legend

Fig. 1 a Local-control probability, b probability of developing new brain metastases, and c overall survival estimated using the Kaplan-Meier method 
A Self-archived copy in

部大学

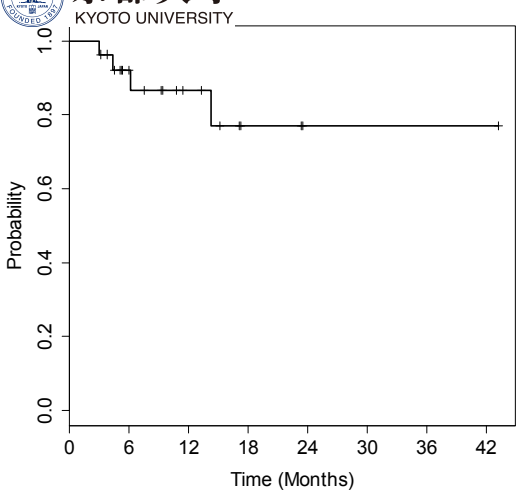

(b) oto University Research Information Repository

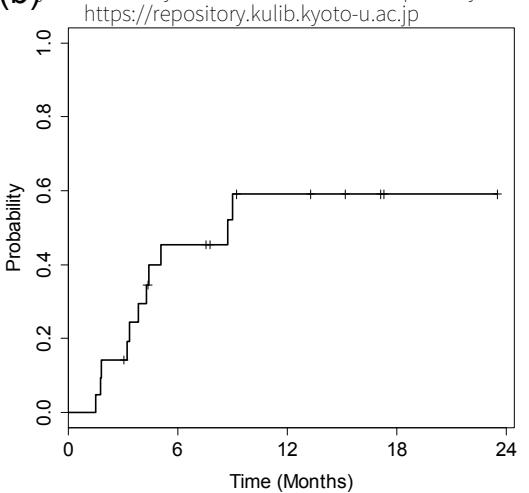

(c)

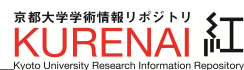

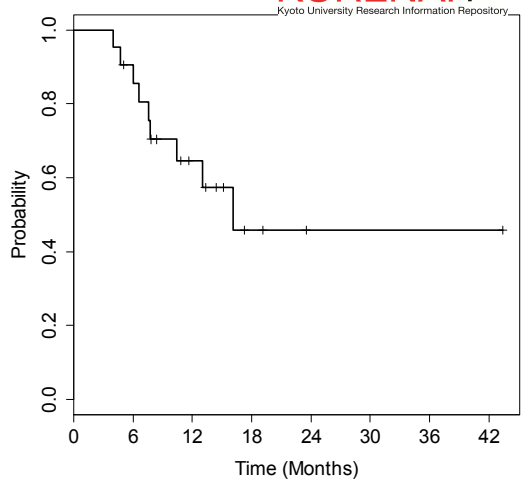


Table 1 Patient and tumor characteristics

\begin{tabular}{|c|c|c|c|c|c|c|c|c|c|c|c|c|c|c|}
\hline $\begin{array}{l}\text { Patient no. } \\
\text { /Tumor no. }\end{array}$ & $\begin{array}{l}\text { Age (years), } \\
\text { Gender }\end{array}$ & KPS & $\begin{array}{l}\text { RPA } \\
\text { class }\end{array}$ & $\begin{array}{l}\text { Primary } \\
\text { tumor }\end{array}$ & $\begin{array}{c}\text { Extracranial } \\
\text { lesion and status }\end{array}$ & $\begin{array}{c}\text { Prior } \\
\text { WBRT }\end{array}$ & $\begin{array}{l}\text { Tumor } \\
\text { location }\end{array}$ & Eloquent & $\begin{array}{l}\mathrm{MD} \\
(\mathrm{mm})\end{array}$ & $\begin{array}{l}\text { PTV } \\
\text { (cc) }\end{array}$ & $\begin{array}{c}\text { Dose/fr. } \\
\text { (Gy) }\end{array}$ & $\begin{array}{l}\text { Local } \\
\text { control }\end{array}$ & $\begin{array}{l}\text { Time }^{\text {a }} \\
\text { (day) }\end{array}$ & Current status \\
\hline 1 & $61, \mathrm{M}$ & 70 & II & Lung & Exist / active & Yes & Temporal & No & 23 & 5.98 & 7 & $\mathrm{C}$ & 95 & Dead (systemic) \\
\hline 2 & $46, \mathrm{~F}$ & 80 & II & Breast & Exist / inactive & No & Cerebellum & No & 28 & 7.11 & 7 & $\mathrm{C}$ & 404 & Alive \\
\hline 3 & $52, \mathrm{M}$ & 90 & I & CUP & None & No & Temporal & No & 34 & 11.16 & 7 & $\mathrm{C}$ & 328 & Lost to follow up \\
\hline 4 & $66, \mathrm{M}$ & 80 & II & Lung & Exist / active & Yes & Brainstem & Yes & 8 & 0.30 & 4 & $\mathrm{C}$ & 181 & Dead (systemic) \\
\hline 5 & $60, \mathrm{~F}$ & 100 & I & Lung & None & Yes & Parietal & No & 10 & 1.04 & 7 & $\mathrm{C}$ & 461 & Alive \\
\hline $6-1$ & $57, \mathrm{~F}$ & 100 & II & Breast & Exist / inactive & Yes & Frontal & No & 28 & 11.40 & 8 & $\mathrm{~N}$ & 1315 & Alive \\
\hline $6-2$ & $58, \mathrm{~F}$ & 80 & II & & Exist / inactive & Yes & Cerebellum & No & 9 & 0.44 & 7 & $\mathrm{C}$ & 711 & \\
\hline 7 & $54, \mathrm{M}$ & 100 & I & Lung & None & Yes & Cerebellum & No & 31 & 10.08 & 7 & $\mathrm{C}$ & 526 & Alive \\
\hline 8 & $39, \mathrm{M}$ & 80 & II & HP & Exist / inactive & No & Frontal & Yes & 28 & 9.78 & 7 & $\mathrm{C}$ & 138 & Dead (systemic) \\
\hline 9 & $49, \mathrm{~F}$ & 100 & II & Lung & Exist / active & No & Temporal & No & 16 & 2.70 & 7 & $\mathrm{R}$ & 187 & Alive \\
\hline $10-1$ & $74, \mathrm{~F}$ & 90 & II & Lung & Exist / inactive & Yes & Parietal & No & 12 & 1.45 & 7 & $\mathrm{C}$ & 521 & Alive \\
\hline $10-2$ & $74, \mathrm{~F}$ & 90 & II & & Exist / inactive & Yes & Brainstem & Yes & 8 & 0.44 & 5 & $\mathrm{C}$ & 521 & \\
\hline $11-1$ & $61, \mathrm{M}$ & 80 & II & Lung & Exist / inactive & Yes & Temporal & No & 27 & 15.38 & 7 & $\mathrm{C}$ & 286 & Dead (neurologic) \\
\hline $11-2$ & $61, \mathrm{M}$ & 80 & II & & Exist / inactive & Yes & Parietal & Yes & 17 & 2.56 & 7 & $\mathrm{C}$ & 286 & \\
\hline $11-3$ & $62, \mathrm{M}$ & 70 & II & & Exist / inactive & Yes & Temporal & No & 19 & 3.67 & 7 & $\mathrm{C}$ & 159 & \\
\hline $12-1$ & $84, \mathrm{~F}$ & 40 & III & Kidney & Exist / active & No & Brainstem & Yes & 3 & 0.08 & 7 & $\mathrm{C}$ & 434 & Dead (neurologic) \\
\hline $12-2$ & $84, \mathrm{~F}$ & 40 & III & & Exist / active & No & Brainstem & Yes & 6 & 0.26 & 7 & $\mathrm{R}$ & 434 & \\
\hline 13 & $54, \mathrm{~F}$ & 80 & II & Lung & Exist / active & Yes & Cerebellum & No & 28 & 5.79 & 7 & $\mathrm{C}$ & 92 & Dead (systemic) \\
\hline 14 & $59, \mathrm{~F}$ & 90 & II & Breast & Exist / active & No & Temporal & No & 18 & 5.08 & 7 & $\mathrm{C}$ & 229 & Dead (systemic) \\
\hline 15 & $71, \mathrm{M}$ & 100 & II & Lung & Exist / inactive & No & Frontal & No & 16 & 2.49 & 7 & $\mathrm{C}$ & 715 & Alive \\
\hline 16 & $68, \mathrm{M}$ & 90 & II & Colon & Exist / active & No & Parietal & Yes & 25 & 4.58 & 7 & $\mathrm{R}$ & 132 & Lost to follow up \\
\hline 17 & $68, \mathrm{M}$ & 100 & II & Lung & Exist / inactive & No & Occipital & No & 23 & 7.13 & 7 & $\mathrm{C}$ & 280 & Alive \\
\hline 18 & $39, \mathrm{~F}$ & 100 & II & Uterus & Exist / active & No & Temporal & No & 28 & 6.28 & 7 & $\mathrm{C}$ & 154 & Lost to follow up \\
\hline $19-1$ & $39, \mathrm{~F}$ & 90 & II & Lung & Exist / active & Yes & Frontal & No & 13 & 0.57 & 7 & $\mathrm{C}$ & 162 & Dead (systemic) \\
\hline $19-2$ & $39, \mathrm{~F}$ & 90 & II & & Exist / active & Yes & Parietal & No & 16 & 2.05 & 7 & $\mathrm{R}$ & 92 & \\
\hline 20 & $65, \mathrm{M}$ & 90 & II & Lung & Exist / inactive & No & Frontal & No & 25 & 6.74 & 7 & $\mathrm{C}$ & 347 & Alive \\
\hline 21 & $53, \mathrm{M}$ & 80 & II & Lung & Exist / active & Yes & Brainstem & Yes & 13 & 1.14 & 5 & $\mathrm{C}$ & 116 & Dead (systemic) \\
\hline
\end{tabular}

${ }^{a}$ This indicates the time between initiation of hypofractionated stereotactic radiotherapy and progression or last imaging follow-up.

Abbreviations: $C$ Controlled; $C U P$ Cancer of unknown primary; $F$ Female; $f r$ fraction; $H P$ Hypopharynx; KPS Karnofsky performance status; $M$ Male; $M D$ Maximum diameter; $N$ Radiation necrosis;

$P T V$ planning target volume; $R$ Relapsed; $R P A$ Radiation Therapy Oncology Group Recursive Partitioning Analysis; WBRT whole-brain radiotherapy 